\title{
ZIVIT VAXBERG
}

Higher Studies Israel

\section{ADOLESCENTS AT-RISK IN THE SITUATION OF TRANSITION: ASSISTANCE PROGRAMS IN THE ISRAELI EDUCATIONAL SYSTEM}

\begin{abstract}
Vaxberg Zivit, Adolescents At-Risk in the Situation of Transition: Assistance Programs in the Israeli Educational System [Młodzież zagrożona w momencie przejścia do szkoły wyższego szczebla programy pomocowe w izraelskim systemie oświaty]. Studia Edukacyjne nr 36, 2015, Poznań 2015, pp. 465-489. Adam Mickiewicz University Press. ISBN 978-83-232-2958-2. ISSN 1233-6688. DOI: $10.14746 /$ se.2015.36.26
\end{abstract}

Adolescents at-risk are defined as adolescents who may be found in physical, mental, or emotional situations of risk. Most of them come from dysfunctional families, poverty, or delinquent social environment. Their problems are expressed mainly in the emotional, educational, social and behavioral realms and lead them to absences from school, low educational achievements, behavior problems, and social difficulties. These problems increase dramatically in the phase of transition from middle school to high school. This transition is characterized primarily by: (a) change from a familiar, intimate place to a large, strange, and anonymous place, (b) change of role - from being the oldest pupil to being the youngest one, and (c) separation from significant adults and friends. The Israeli educational system has developed special assistance programs for the transition phase of adolescents at-risk. These programs operate in two parallel and complementary dimensions. During school time, there are special programs such as psychodrama groups which are aimed at strengthening the learners' perseverance and increasing their success in the normative frameworks. After the school hours, the programs provide them with activities such as mental support and help in their homework preparation.

Key words: adolescents at-risk, transition programs, Israeli educational system

\section{Adolescents At-Risk}

The concept of adolescents at-risk describes the population of children who are found or may be found in physical, mental, or spiritual situations of 
risk. Dryfoos ${ }^{1}$ maintains that about one half of all children and youths, aged ten to seventeen, are at-risk, when about one-quarter of them are found at a high risk. In contrast, Glenn and Nelson ${ }^{2}$ maintain that all children are potentially in some situation of risk.

Nowadays, the specific definition of a child as one who is at-risk and the evaluation of the level of this risk are performed today by experts from the different treatment professions.

\section{Adolescents At-Risk in Israel}

Children at-risk are defined by the welfare authorities as living in situations that endanger them in their family and in their environment, and as a result of these situations their ability to realize their rights is harmed in the areas of physical existence, health and development, belonging to the family, learning and acquisition of skills, welfare and emotional health, belonging and social participation, protection from others and from their own endangering behaviors ${ }^{3}$. In Israel, in recent years, there are more than two million children. Of these children, approximately 350,000 children and youths are defined as found in situations of risk and distress. Among them $40 \%$ suffer from verbal violence, $18 \%$ from physical violence, and 5\% suffered from sexual assault ${ }^{4}$. The concept of children at-risk ranges on a continuum when levels of risk are expressed in the composition of a number of different areas in which the problem exists, in the severity of the problem in each field, and in the duration of time that the child suffers from the problem or problems. In general, it can be said that at one end are found those defined as at low risk and at the other end are those defined as at high risk ${ }^{5}$.

The treatment approach accepted in Israel divides the population of children at-risk into three primary groups:

1. Children and youths found in direct and immediate danger - these are children who are victims of abuse and neglect, children and youths with behavior problems, delinquent youths, youths who use drugs, and victims of abuse in the family.

${ }^{1}$ J.G. Dryfoos, Adolescents At Risk: Prevalence and Prevention, New York 1990.

${ }^{2}$ H.S. Glenn, J. Nelson, Raising Self-Reliant Children in a Self-Indulgent World: Seven Building Blocks for Developing Capable Young People, California 1988.

${ }^{3} \mathrm{H}$. Shmidt, The Prime Minister's Committee for Children and Youths At-Risk, Report of the Public Committee for the Examination of the Situation of Children At-Risk and in Distress, 2006.

${ }^{4}$ Ibidem.

${ }^{5}$ D. Ben-Rabi, P. Kahan-Starvinsky, Planning Services and Interventions for Children and Youths at the Edge of the Risk Continuum, Jerusalem 2003. 
2. Children and youths who live in an endangering environment and are found in indirect risk - these are children who witness violence between their parents, addiction, delinquency, children who live in poverty, and children who live in communities that endanger them.

3. Children and youths who live under circumstances that may create risk - these are children from families that are suffering a crisis because of divorce, single-parent families, families that suffer from unemployment, and immigrant families.

The results of this situation of risk may lead the children in terms of personality to have low self-esteem and behavior problems, to suffer from alienation and rebelliousness, deficient social skills, isolation, and social rejection, to have a tendency to evade dealing with situations and difficulty meeting social pressures, and sometimes even to have deviant and/or delinquent behavior.

The educational influences also are apparent. It was found that the educational achievements of these children are significantly lower than those of their classmates, and this situation frequently causes them to drop out of the studies.

To understand the problems of adolescents at-risk, it is necessary to understand the developmental tasks of adolescence in general, and the unique problems of this age. These are discussed in the following section.

\section{Developmental Tasks of Early and Late Adolescence}

The term 'adolescence' is derived from the Latin word adolescere, which means to grow or to mature. A large number of definitions have been formulated for this period of time, including period of transition or bridge between dependent childhood to adulthood, when the requirement of the adult person is to provide his own needs. Other definitions are more operational, such as a period that requires personal, sexual, religious, political, and professional adjustment, along with the steadily increasing aspiration for emotional and financial non-dependence on the parents.

Adolescence is a topic that has been widely addressed by Western society, starting from the beginning of the $20^{\text {th }}$ century. The concept of adolescence notes a period that differentiates between childhood and adulthood and appears first at the end of the $18^{\text {th }}$ century. For the first time, in this era young people were not integrated in the work cycle and they could continue with their studies. This process became more widespread from the beginning of the $20^{\text {th }}$ century. It should be noted that the interest in adolescence 
increased after the publication of the book Adolescence by Hall6 in 1904. This book, for the first time, presented a theory about adolescence. Over the years additional theories on adolescence were developed, and they will be presented in the continuation of the chapter.

It is possible to look at adolescence from different aspects. Chronologically this is the period of time between the age of twelve and the early twenties (the period changes according to the specific society and culture). Sociologically adolescence constitutes a transition from the period of childhood, which is characterized by the utmost dependence on the parents, to adulthood, which is characterized by independence. During adolescence it is possible to discern physical, mental, and emotional changes. Biologically the lower bound of this period is accompanied by processes of sexual maturation and fertility. For instance, in primitive society it can be seen that after sexual maturation the adolescent receives the status of an adult, while in developed societies the period of adolescence is extended. The upper bound of adolescence is not as clear as the lower bound, and it is not possible to discern a concrete physiological phenomenon that will indicate the end of the process. Therefore, it is possible to address the upper bound from the social aspect, namely, economic independence, employment, marriage, and establishment of the family, and all these constitute indicators of psychological independence.

It is important to note that in most cultures two criteria are used to determine the end of adolescence. The first criterion is a functional definition, which addresses the adolescent's ability to earn a living, while the second definition address a class definition, which addresses the right to vote (at the age of eighteen), the right to marry, and the right to serve in the military. The class definition changes from country to country, but in most countries the age of eighteen is considered the age that denotes the end of adolescence. Today in Western society the period called adolescence is longer than it was in the past, since sexual maturation begins earlier and because of the greater years of study required of the young people so that they can prepare for their future occupations ${ }^{7}$.

Adolescence is characterized by the conflict between, on the one hand, biological maturity, fertility, and biological equality to the parents, and on the other hand, the continuation of the economic and social dependence on the parents. This conflict explains many characteristics of adolescence. The adolescent shapes his personality in this period and arrives with a value-

${ }^{6}$ G.S. Hall, Adolescence, New York 1904.

${ }^{7}$ L. Sroufe, R. Cooper, J. Dehart, The Development of the Child: Nature and Process, Volume 2, Tel Aviv 2004. 
oriented mindset that he absorbed during the years of his childhood, and he puts them to the social test. This mindset, laden with the rules upon which he has been educated, conflicts with the social reality. The adolescent implements his independence and identity in the examination and experience with the world of adults 8 .

In general terms, it is possible to divide the period of adolescence into the following three periods:

- Early adolescence addresses ages 12-14. It primarily indicates physical changes, sexual maturation, and reproductive capacity.

- Middle adolescence addresses ages 15-17. This is the period of the high school, which is characterized by steadily increasing independence, preparation for the continuation of the studies, and preparation for the term of military service (in countries where such service is mandatory after high school).

- Later adolescence addresses age 18 and up, till the early twenties. At this age the adolescent achieves a clear sexual identity, which enables him to create a significant emotional relation with members of the opposite sex. The adolescent at this stage has a forming identity, which looks at the future. There are thoughts about profession, studies, and independent existence in society. ${ }^{9}$

Havighurst ${ }^{10}$ proposed that stages in human development can best be thought of in terms of developmental tasks that are part of the normal transition. Havighurst believed that the developmental task is the midway between an individual need and a social demand. He identified eleven developmental tasks associated with the adolescent transition:

1. The adolescent must adjust to a new physical sense of self.

2. The adolescent must adjust to new intellectual abilities.

3. The adolescent must adjust to increased cognitive demands at school.

4. The adolescent must develop expanded verbal skills.

5. The adolescent must develop a personal sense of identity.

6. The adolescent must adjust establish adult vocational goals.

7. The adolescent must adjust establish emotional and psychological independents from his or her parents.

8. The adolescent must develop stable and produced peer relationships.

9. The adolescent must learn to manage his (or her) sexuality.

10. The adolescent must adopt a personal value system.

\footnotetext{
8 A. Elitzur et al., Selected Chapters in Psychiatry, Tel Aviv 2002.

9 Ibidem.

${ }^{10}$ R.J. Havighurst, Developmental Tasks and Education, $3^{\text {rd }}$ Ed, New York 1972.
} 
11. The adolescent must develop increased control and behavioral maturity.

In Israel, the induction of the adolescent into the military defines the adolescent's duty and civil responsibility as well as independent standing. The military indicates the end of adolescence and the transition to adulthood, because of the following characteristics: equal treatment of each draftee and transition from age of deliberations and arguments to an authoritarian and uncompromising framework that negates rebelliousness. In addition, the military service causes the loss of privacy. The adolescent, who until now was careful to maintain his own territory, must adjust to shared and uniform life and share joint property. The military framework brings about apparent changes, which lead in the continuation to functional and social independence according to the circumstances of development. With the end of the military service, the adolescent faces new tasks and challenges, when the emotional mindset is now the sum of the experiences and interpersonal relations from childhood through adolescence, with the additional shaping provided by the military service ${ }^{11}$.

One of the main problems experienced by adolescents is the transition from middle school to high school. This transition reflects the problems of transitions in general, which are discussed in the next section.

\section{Transition}

\section{Definition of the Concept of Transition}

Transition is defined as a change or progress from one place, action, situation, or topic to another one. Many researchers, including Steinberg12 and Yinon and Rodniki ${ }^{13}$, have defined the topic of transitions and have presented different approaches regarding coping with changes in the transition from the middle school to the high school.

Transition to a new learning framework is a normative life transition. During the transition, the student may experience increased pressure and sensitivity to the changes to which he must adapt. In a transition the individual may experience behavior problems, decline in the scholastic achievements, increase of anxiety, primarily regarding social issues (acceptance by

11 A. Elitzur et al., Selected Chapters in Psychiatry.

${ }^{12}$ L. Steinberg, Identity. Adolescence, Boston 2002, p. 255-285.

13 Y. Yinon, Y. Rodniki, Influence of the Rise to the Middle School on the Student Anxiety and Aggressiveness as a Function of Social-Economic Status, Studies in Education, 2003, 5(2), p. 81-98. 
the peer group), and the need to meet the expectations of the new learning environment. These issues may cause a decline in the self-esteem and selfimage and a rise in the psychological distress experienced by the individual. The influence of the scholastic transitions on the individual is great. As aforementioned, scholastic transitions influence the individual's system of self, which includes:

- Emotional elements (sense of self-esteem).

- Cognitive-motivational elements (expectations of effective functioning in the scholastic and social fields).

- Behavioral elements (manner of functioning in the scholastic and social areas).

There are a number or variables that mediate between the occurrence of the transition and the coping of students with it. These variables may determine the degree of adjustment to the new learning framework:

1. Student's psychological characteristics, such as personal abilities, patterns of coping, and level of autonomy.

2. Family characteristics, such as socioeconomic situation and parenting style.

3. School characteristics, such as complexity and difficulty of the tasks and degree of social and emotional support.

The review of the different variables that influence the individual's degree of adaptation to the new learning environment indicates that the environmental factors have considerable influence. Beyond the student's personality characteristics and socio-demographic background, the old learning environment, the new learning environment, and the degree of coordination and continuity between them have considerable weight in terms of their influence on how the student will handle the transition.

\section{Theories Addressing Transitions}

Many research studies have addressed the topic of transitions. Erikson ${ }^{14}$ speaks about how the person's development depends on his ability to successfully cope and deal with the different transitions in every stage of his life. A person is not born with abilities and skills to pave his way in the complicated maze of changes in his life. He learns them and develops personal strength for independent coping. Adolescence is characterized by a great number of biological, cognitive, emotion, and social changes. These

${ }^{14}$ E.H. Erikson Childhood and Society, Tel Aviv 1960. 
changes embody great potential for experiences of emotional difficulty, which increases the adolescent's sensitivity to pressuring life events. Adolescence is a significant stage in the process of development, a stage during which the child's personality undergoes, in addition to biological changes, changes at the end of which the adolescent will achieve the crystallization of his personality and self-identity. The adolescent is required to complete a number of tasks, when one of the tasks is to shape his identity while separating from his parents and moving towards his peer group. The adolescent is required to cope with additional difficulties, in parallel to the developmental task of the stage in life in which he is found. In this stage, during the difficulties, the belonging to the group may contribute greatly, both in terms of the different struggles that the age brings and in terms of the belonging to the peer group.

Erikson ${ }^{15}$ developed a model based on stages and held that each one of the stages is characterized by a conflict with two possible outcomes, which give the stage its name. Erikson called the stage of adolescence, ages 12-18, the stage of identity versus role confusion. Blos ${ }^{16}$ spoke about the "second process of individuation". The task at this stage, in his opinion, is disconnection from the dependence on the parents and the other family objects of love, until an object of love outside of the person and his family is found. This process requires disconnection from the parents and temporary closeness with the peer group. However, the group requires the adolescent to submit to its standards in return for the security it grants. The danger is that one mode of dependence, on the family, may be replaced with another one, on the group. Conversely, an adolescent who will not adjust himself to the model of 'uniformity' may be exposed to mockery and denial.

The main task at this age is the formation of the personal identity. The adolescent separates in stages emotionally, intellectively, and socially, from the main figures in his family and shapes himself as an entity with a separate personal identity. The process of the separation from the parents and the freedom from the dependence is undertaken with alienation, rebellion, and hostility towards the parents. This is a normative process, regular for adolescence. The adolescent examines the boundaries of what he does and what he is entitled to do. In parallel, there is the desire to continue to be little, dependent, and supported. In the social realm the adolescent is steadily more occupied with the development of relations with friends, development

\footnotetext{
${ }^{15}$ Ibidem.

16 P. Blos, On Adolescence, New York 1962.
} 
of a system of relations with members of the opposite sex, and ability to fit into the social order ${ }^{17}$.

Antonovsky18 in the metaphor of the "river of life" addresses different levels of preventative intervention necessary in work with adolescents. There is a large group of adolescents who are found "on the river bank" and need a universal initial preventative program to equip them with knowledge and abilities for the coping with the changes entailed by the transition. There is a not-small group of students "who have fallen or may fall into the water in the river upstream" and who are found at risk in the transition, including at-risk students. This is the group for whom this program is intended. In every population of students there are also students who have "fallen into the water and have been swept away down the river" and they need a tertiary level of intervention - the treatment of professionals outside of the school system in general and in the context of the transition in particular.

Feuerstein ${ }^{19}$ speaks about three responses that are characteristic of situations of transition. (1) Aloplastic response - When the person is threatened, he goes to struggle against the source of the threat so as to be released from it (fight). (2) Flight response - When the person is found in a situation of danger, he protects himself by running away, for example, running to risky behaviors. (3) Autoplastic response - When the person is threatened, he responds by changing himself, developing thinking and learning abilities, and produces benefit from his different experiences. All these require flexibility, self-development, and ability to re-invent different means so as to adjust to new situations with which the person conflicts. The goal of the intervention program is to prepare for the processes of transition, and its purpose is to ensure that the transition will not end with an aloplastic response or with flight but will encourage autoplastic responses of adjustment to the new conditions and change of the self through the use of the previous experiences and identification with values and goals in life.

Turner ${ }^{20}$ focuses the discussion on rites of passage. He extends the analytical framework of Van Gennep, according to which ritual conduct is composed of a process of three stages. The first stage is disconnection from the flow of everyday activity. The second stage is transition through a liminal state to the ritual world, which is distant from the framework of the everyday concepts of space and time, the framework where he gains the everyday

17 A. Ziv, Adolescence, Tel Aviv 1984, p. 13-30 and 81-98.

18 A. Antonovsky, The Salutogenic Model, Trends, 1987.

${ }^{19} \mathrm{R}$. Feuerstein, Lecture on the Topic of Transitions in Education, from: Transitions in Education, Shachar Department - Ministry of Education, 1981.

${ }^{20}$ V. Turner, The Ritual Process: Structure and Anti-Structure, Ressling, 2009. 
structures of life for development and for challenge. The third stage is reentry into the everyday world. In the liminal stage the most important drama occurs, relating to the everyday norms through the performance of socially subversive and ritually opposite activities. Therefore, Turner's starting point adamantly rejects the main and dominant conventions in socialcultural anthropology in general and in British anthropology (according to which he was educated) in particular - the intention is the assumption of the obedient nature of people. One of the key concepts related to the second stage (liminality) that provides many insights in anthropological analysis is communitas, the sense of fraternity that exists among people who have experienced a rite of passage together. This concept excited the imagination but also awakened strong debates about the very possibility of the creation of a sense of fraternity that eliminates hierarchies among people. Can religious experiences create, if only for a moment, partnership and equality among all those who share the religion?

\section{Factors and Influences of Transitions}

There are many causes of transitions. There are planned transitions and desired transitions, and there are unexpected transitions and forced transitions.

Transitional situations can be normative or non-normative. Normative transitions include the transition from one grade to the next, while nonnormative transitions include divorce, becoming an orphan, a move to another neighborhood, city, and/or country, and a move to a different school. There can be a move within a move, for example to a middle school in another city.

For every transition, it is important not to ignore it and to include it in the planned scholastic/social transition. Sometimes the student chooses to transfer to a different school because of social or scholastic difficulties that he experiences in the present framework.

When the transition is forced, for example, when the framework decides to shift the student because of lack of fit, the problems of the transition are exacerbated further. As the transition is more complex and integrates transitions in different areas, it is expected that there may surface more sensitivities related to areas such as family and ethnic-cultural, socioeconomic, and other areas.

During adolescence, there is a dual transition. The adolescent experiences adolescence, with its changes, and enters a new scholastic framework, 
which is far larger, has a different structure of learning, and is oriented far more on formal achievements.

The changes in the transition are expressed in a number of areas, as follows:

- New social relations versus disengagement from the friends in the previous framework

- Adjustment to a new learning method

- Adjustment to new study subjects, requirements, grades

- New norms, rules, "do's and don'ts"

- Reversal in the student's status and loss of scholastic and social status and a decline in the self-image

The most significant transition for adolescents is the transition from middle school to high school, which will be discussed in the next section.

\section{Coping with Changes in the Transition from Middle School to High School}

The transition from the middle school to the high school is frequently a dramatic transition. This is a transition from a familiar place to a strange place, with the separation from the familiar significant adults, separation from friends, transition from an intimate framework to a large and seemingly anonymous framework, and change of role - from being the oldest to being the youngest. This transition frequently entails distance from the home, the need for travel, and so on. In essence, the transition necessitates the ability to adjust to many structural and human needs. The acquisition of tools that enable better

Coping with the transitions in the stage of adolescence is essential to the development of the ability to cope with future situations of change and to the development of personal and cognitive flexibility and facilitates the future integration.

The ability to think positively also in difficult or pressuring situations, the ability to cope with difficulty, and even with failures in different situations, and the ability to see localized difficulty as an opportunity for future change are all a part of the basic toolkit necessary for the construction of the resilience and the personal coping.

Adolescence constitutes a critical stage in the formation of the adolescent's self-identity, in which the question of "who am I?" becomes central and essential in his life and is often accompanied by crisis, confusion, or examination of the identity. Simultaneously with the development of the physical 
and intellective abilities and in parallel to the formation of the personal identity, the adolescent acquires independence: he now needs his parents' assistance less and can get along by himself and make decisions himself, when the company of his peers helps him reduce his dependence on his parents.

The acquisition of independence is frequently accompanied by fears, since independence has a cost and not only a profit: a person who decides by himself and does things by himself is also responsible for the results of his decisions and actions. The assumption of responsibility demands mental resilience and the ability to pay the price of independence.

Adolescents want, on the one hand, to be independent, to go to a place they want, to do as they want, and to return when they want. However, on the other hand, it is hard for them still to decide by themselves and it is hard for them still to bear the responsibility for the results of their actions. Therefore, they sometimes display independence and sometimes dependence.

The adolescent's ability to cope with the need for the formation and development of independence reflects an essential and critical process. The adolescent's ability to assume responsibility for different processes and for main junctures in his life and his ability to represent himself and to manage himself in a responsible manner, with an opinion and outlook when dealing with different factors, are vital to the continuation of his adult life.

\section{Transitions in the Educational System in Israel}

In Israel the educational system has a tripartite structure: elementary school, 6 years, from age 6 to age 12; middle school, 3 years, from age 12 to age 15; and high school, 3 years, from age 15 to age 18 .

There are many enrichment programs for the transition from the middle school to the high school, looking at the transition and the unique characteristics and needs, in areas such as the cognitive, physical, emotional, and social areas. Intervention programs are constructed to create a social scholastic continuum in the transition, while increasing the sense of security, confidence, and continuity among the students, educational staff, and parents.

The programs include obligating procedures that will institutionalize the processes of the transitions, as well as instruments that were developed together in an absorbing and nurturing framework, for follow up after the students and for the improvement of the quality of the transition ${ }^{21}$.

${ }^{21}$ A. Binstock, Kit On Normative Transitions in the Educational System, 2004, From: The Psychological Counseling Service Website, In The Ministry of Education Website, Www.Cms. Education.Gov.Il. 


\section{The Transitions Model}

Normative \& Main Developmental Transitions in the Educational System

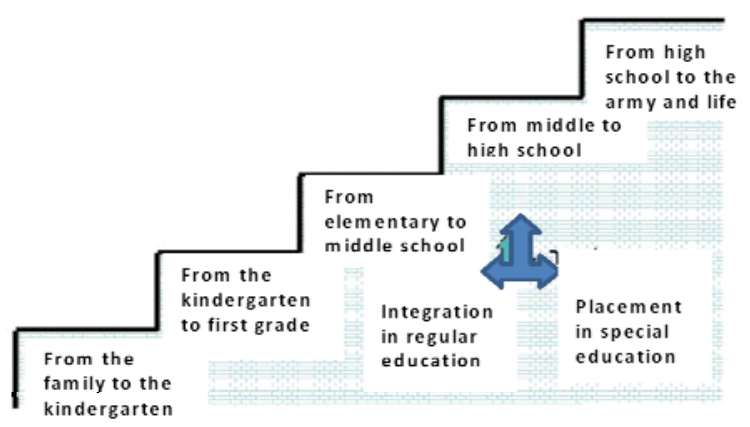

Change in Lifestyle

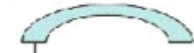

Birth of Divorce

$-1$

Adoption Loss

|

Health

I

Migration

| Religion

Vegetarianism

Fig. 1. The Israeli Transitions Model

\section{The Transition Program of the Israeli Education Ministry}

\section{Program Objectives}

- To improve the ways of coping of teachers and students in the school with the transitions between frameworks

- To support the processes of emotional, social, and scholastic adjustment of the students to the new framework

- To promote the awareness and involvement of the parents in the stages of the transition and the educational continuum of their children

- To reinforce the relation between the educational frameworks while pooling resources in the community

- To develop a shared language among the educational staffs in the community for the building and adjustment of the educational continuum

- To reinforce the partnerships between the parties involvement in the program management (principals, teachers, supervision, local authority) to leverage the empowerment of the schools and the educational staffs 


\section{Description of the Work Process}

The principal's responsibility in the school is to implement the program "Towards Transition". In cooperation with the school psychologist, the principal must hold a workshop for teachers, to train them to effectively cope with the topic of the transitions both on the personal level and as instructors of those who learn in the classes of "Towards Transition", as an active and present part in it. The members of the work group will build and implement the transitions program in a collaborative process of learning and agreement among the subject coordinators, social education coordinators, counselors, and teachers in both the frameworks.

In every local authority there will be a steering committee and from the policy of the Ministry of Education and a program of the transition in the national continuum, and its roles are:

- The community steering committee for handling educational transitions and continua. The steering committee will choose for the chairperson the general supervisor / head of the department of education in the local authority. The steering committee will include the institutions and the roleholders, such as the local authority, social psychological service, the Ministry of Education, Welfare, Community Center, and so on.

- The steering committee will hold activity to promote the awareness and recognition of the leaders of the educational system (supervisors, local authority, principals on both sides of the transition) in the importance of the formation of the community program for transitions and educational continua.

- The steering committee will operate to form a program of continuation in the core subjects and in the emotional-social realm, which will include objectives, actions, topics, contents, and measures that obligate the entire educational system in the community.

- The steering committee will receive regular updates regarding the program, will identify focuses of difficulty in the implementation, and will form alternative solutions.

\section{Programs}

\section{Students:}

Workshops in groups on topics of:

- Empowerment and strengthening

- Providing tools for the development of personal and social skills 
- Increasing the value of, perception of, and belief in the self

- Coping with social pressure through the internalization of new behavior norms

- Coping with test anxiety

- Relations between the sexes and intimacy

\section{Parents}

Workshops on the topics of:

- Adolescence and its different characteristics

- Liberation and separation

- Beneficial parental authority

- Help in processes of the student's choice of programs of study for the high school matriculation examinations.

\section{Teaching Staff}

There are four sessions. The staff undergoes a process of emotional airing-out and enriches the repertoire of instruments for coping with situations of transition. In parallel, the teachers work on building lesson plans on the topic of transitions, and they conduct these lessons with their students in the classes towards the end of the school year. The topics include:

- The teacher's conflicting with her needs and expectations and increase of her self-awareness of patterns of emotion, thinking, and behavior in situations of change and crisis.

- The enrichment of the repertoire of ways of coping intended to reduce difficulties in the present and in the future through the BASIC Ph Model22. This model defines six styles of coping:

1. Belief. These youths prefer to rely on beliefs, values, and search for meaning. This type may rely on hopes, optimism, pessimism, and paternalism and on mysticism and use of rites.

2. Affect. These youths use an emotional style. They tend to use emotions such as laughter, crying, and anger and they ask for emotional support from others. They express themselves in nonverbal ways such as writing and drawing.

3. Social. These youths are characterized by a social coping style. These youths draw support from their belonging to the group, stick to the family, and receive or assume a role for themselves. The belonging to an organiza-

22 M. Lahad, Basic Ph: The Story of Coping Resources, [in:] Community Stress Prevention, Volumes 1 and 2, Eds. M. Lahad, A. Cohen, Israel 1997, p. 117-145. 
tion or group helps him, and they position themselves in the social hierarchy.

4. Imagination. These youths will use imagination to ease a difficulty reality. They will use social activities, distractions (music, television), daydreams, and pleasant thoughts. These youths will use guided imagination to find solutions that go beyond the facts. They have a sense of humor and creativity.

5. Cognition. These youths will use cognitive thinking to collect information. They will think about the solution to the problems and will build programs while learning from experience, searching for alternatives, and using a list of priorities.

6. Physiology. These youths cope and respond primarily through physical expressions, namely, physical responses and emotions. They will use relaxation, sport, physical activity, and other actions as ways of relief.

\section{Responsibility for the Workshop Program}

The main task of the person running the intervention (parent, careprovider, teacher, and so on) is to restore the youths to functioning through the identification and awakening of their channels of coping or through the development and extension of channels of coping characteristic of them. We must listen to the youths' distress, attempt to identify their patterns of coping, and offer ways that suit their personal style. In addition, it is important to expose the youths to additional coping styles, since in this way the youths can acquire a greater repertoire of resources they can use as necessary.

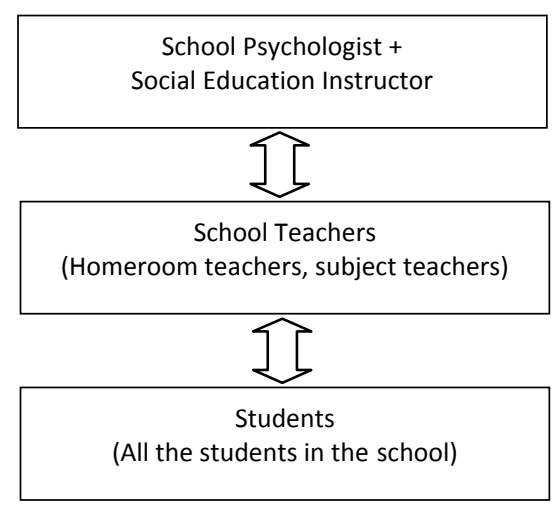

Fig. 2. Relations among the Factors in the School Intervention Program 
- Cultivation of communication skills, increase of the ability to understand others, and creation of cooperation with others.

- Construction of lesson plans on the topic of transitions, with the help of the social education instructor.

\section{Instruction}

Instruction is provided for the following parties, according to the following aspects:

- All the school teachers

- The school psychologist (psychologist aspects)

- Social education instructor (pedagogical aspects of social education)

- Instructor of the school assessment staff (evaluation and measurement aspects)

- The school principal (supervision and follow-up)

The problems that adolescents experience in a period of transition are further exacerbated in the case of adolescents at-risk, who experience also their own unique problems and difficulties.

\section{Adolescents at-Risk and Transition}

The process of the transition from the middle school to the high school increases the difficulty in the coping of adolescents at-risk with the new requirements. These problems increase dramatically in the phase of transition and do not address the issue of adolescents at-risk, for whom coping with changes has a double risk, since they are defined as at-risk in emotional, cognitive, behavioral, and social terms. The characteristics of adolescents at risk include:

(a) Change from a familiar, intimate place to a large, strange, and anonymous place.

(b) Change of role - from being the oldest pupil to being the youngest one.

(c) Separation from significant adults and friends.

The main assumption of the research is that it is necessary to understand the double risk that this population faces in the transition and it is necessary to adjust tools and skills specifically for these children, so as to facilitate their coping with the many changes entailed by a transition. Because of the high 
risk, adolescents at-risk have not only the regular formal programs of transitions in general but also additional programs, 24/7, which aim to provide a solution to the additional difficulties of these children. The great difficulty is the family difficulty, and with it the matter of support and the lack of a father/mother figure, which constitutes a 'significant other', a 'parental figure', which they need in the transition to the school.

\section{Treatment of Children At-Risk in the Formal and Informal Educational System}

To treat and to provide a solution for children at-risk at all hours of the day, the educational system operates in two parallel and complementary dimensions. First, the educational system works to strengthen the learners' perseverance and to increase their success in the normative frameworks. Second, the educational system strives to provide activities in the framework of informal education and other frameworks after the end of the studies, for example, clubs in which the children spend the afternoon hours, receive a hot meal, and are given mental support and help in the preparation of homework ${ }^{23}$.

Regarding the schools, programs for schools outline special organizational, pedagogical, social, and budgetary instruments to provide an answer to the needs of the population at-risk. In the framework of one program, some of the children defined at-risk participate in psychodrama group activity 24 .

\section{Formal Perspective}

From a formal perspective, all the programs were developed in the Transitions Model25, and additional programs were developed by every municipality separately, according to the needs of its residents, and emphasize especially the specific problems of adolescents at-risk.

${ }^{23}$ S. Dovrat, The National Plan for Education: Report of the national Task Force for the Promotion of Education in Israel, Jerusalem 2005.

${ }^{24}$ M. Cohen-Navot, School Intervention for Children and Youths At-Risk, Special Report, Background Document For Eshelim, [in:] The Framework of The Formation of a Three-Year Work Plan, 2004-2006, Jerusalem 2003.

25 A. Binstock. Kit on Normative Transitions. 
During school Time:

A. Special effort in locating these children

B. In the studies: additional lessons to help these children

C. Emotional realm: additional psychological counseling hours

D. Development of special programs such as psychodrama groups aimed at strengthening the learners' perseverance and increasing their success in the normative frameworks.

This program was developed by the researcher with the aim of helping adolescents at-risk with the different environmental conditions that require emotional, scholastic, and social adjustment in the transition from the middle school to the high school. Participation in the group program offers conditions for the individual to build personal and social skills so as to facilitate the dealing with the turbulence of the transition. The integration of psychodrama contributes to the individuals' emotional release through their experience of different situations in the transition through role play.

\section{Structure of the Program}

The program is an annual program held in the ninth grade and before the transition to the tenth grade. The program is built of four stages:

1. Identification of adolescents and recruitment to the program.

2. Individualized conversations to identify gaps, inhibiting factors in the emotional, social, and scholastic fields.

3. Implementation of the program - opening the group, preparation of a group contract, coordination of expectations on the meetings to be held during the group dynamic.

4. Separation from the group.

\section{Objective}

To increase the sense of self-worth and belief in the self of adolescents atrisk in the transition from the middle school to the high school.

\section{Goals of the Program}

- To promote the powers and strong points.

- To provide tools for the development of personal and social skills.

- To promote the value, perception, and belief in the self.

- To cope with the social pressure through the internalization of new behavior norms. 


\section{The Meetings in the Program}

The adolescent at-risk copes in the 'here and now' with traumas and different difficulties, such as the family circle of divorced/separated parents and/or data with personal/economic problems, and this in addition to his difficulties. In the meetings in the program the adolescents will obtain tools for the strengthening of the sense of efficacy, for the development, and acquisition of personal skills for the improvement of the self-image through learning and experience of group dynamics in the integration of psychodrama.

\section{Treatment of Psychological and Social Problems through Drama}

Participants:

- Instructor

- 'Heroes of the drama'

- Group members

Psychodrama enables the reconstruction of the participant's experiences in the framework of the peer group and with the help of its members. In psychodrama, through physical and verbal action, the participant relives the parts of his life that he can investigate from raising feelings, observation, and coping. After the action it is possible to change the events, reorganize what is clear, and find alternatives for coping with highly charged topics ${ }^{26}$.

\section{Definition of Psychodrama}

Psychodrama, developed by Moreno27, is a method in group psychotherapy that constitutes a part of the methods of art therapy. The word psychodrama is composed of two words in Greek: psyche (mind, soul) and drama (action). In other words, it means the mind in action. The work method in psychodrama is based on dramatic action and role play through which the participant presents problems, difficulties, and personal and interpersonal difficulties as well as solutions and ways of coping, so as to reveal the individual's inner world, understand his system of relations, and clarify patterns of behavior. Through psychodrama it is possible to change inadequate and/or undesired situations and responses and to act in new and more suit-

26 E. Artzi, Psychodrama, Dvir Press 1991; H.A. Blatner, Acting In Practical Applications of Psychodrama Methods, 1973, p. 27-30.

${ }_{27}$ Z.T. Moreno Psychodrama, Surplus Reality and the Art of Healing, London and Philadelphia 1921. 
ed ways, such as the identification and release of emotional barriers so as to achieve mental balance ${ }^{28}$. Psychodrama enables the participant, through physical and verbal action, to reconstruct his experiences, in the framework of the group and with the help of the group members. In this way, psychodrama accompanies the participants into their inner world, which they describe and express in drama. Through the group activity in psychodrama, the participant has the possibility of experiencing a corrective experience of the original event, of changing his perspective on it, and of finding alternatives for coping with the loaded mental topics ${ }^{29}$.

Psychodrama enables the reconstruction of the participant's experiences in the group framework and with the help of the other group members. In psychodrama, through physical and verbal activity, the participant relives parts of his life, which he can investigate from the raising of feelings, observation, and coping. After the activity there is the possibility of changing the events, re-organizing them for clarification, and finding alternatives for dealing with the loaded topics ${ }^{30}$. Dayton ${ }^{31}$ maintains that psychodrama is a method of treatment in which emotions that have been repressed in the past are released and surface in the present, all in an atmosphere that inculcates a sense of safety and holding.

"Psychodrama is a method in psychotherapy in which patients are encouraged to continue and complete unfinished issues through dramatization, role play, and dramatic self-presentation. The instructor uses verbal communication. A number of scenes are acted out and describe memories from the past, inner dramas, fantasies, dreams, preparations for future situations, and expressions of mental situations in the here and now. Scenes represent situations in life itself or inner mental processes. The members of the group take on roles as needed. Some of the techniques are role reversal, double, mirror, concretization, and so on. The stages of the encounter are warm-up, dramatic action, and conclusion that include sharing ${ }^{32}$. Psychodrama enables reconstruction of the participants' experiences in the framework of the group and with the help of its members. In psychodrama, through physical and verbal action, the participant relives parts of his life, which he can study from the raising of the feelings, observation, and coping.

${ }^{28}$ Israeli Association for Psychodrama. http://www.Iafp.org.il/.

${ }^{29}$ E. Artzi, Psychodrama; H.A. Blatner, Acting in Practical Applications, p. 27-30; E. Naharin, A Stage instead of a Sofa, Tel Aviv 1986.

30 Ibidem.

31 T. Dayton, The Drama Within: Psychodrama and Experiential Therapy, Deerfield Beach, FL 1994.

32 F.K. Kellerman, Focus on Psychodrama: The Therapeutic Aspects of Psychodrama, Philadelphia 1992. 
After the action it is possible to change the events, to re-organize what is clear, and to find alternatives for coping with charged issues ${ }^{33}$.

According to Dayton ${ }^{34}$, psychodrama is a therapeutic method in which emotions that had been repressed in the past are released and flood the present - all in an atmosphere that inculcates a sense of security, holding, and protection. Psychodrama accompanies the patients into their inner world, while they describe it and express it dramatically. The psycho dramatist helps the person (the patient) raise to the surface contents that had been deeply hidden. This action serves as a trigger of emotion that accompanies the contents from the unconscious to the conscious. The emotion is experienced as it originally had been, and the mind can re-examine the contents according to their re-editing. Last, the instructor "returns" the protagonist to the group through "sharing". At the end the natural forces of healing of the mind continue with their work, towards illumination of the materials that are supposed to be examined. The process enables the entry into the person's inner reality and validates it as it exists, without the intention to change or adjust it according to the opinions of other people. Psychodrama also enables the remedial experience of the original event.

Karp and Homs ${ }^{35}$ addressed psychodrama as therapy that does not label. Psychodrama investigates unique situations and 'normalizes' them, focuses on health and not pathology: this is one of its great advantages. Another essential element that adds to this advantage lies in the work of the therapist/instructor: he is more a partner than in any other therapy method, where he usually observes from the side, interviews, etc. Here, under his guidance, with his body language, mimicry, the emotions are revealed and exposed, since he is found in a situation of sharing of the self as a part of the creation of the process on the stage. In addition, he has the option of sharing his own personal contents during the "sharing".

\section{Basic Concepts in Psychodrama}

Spontaneity: According to Moreno ${ }^{36}$, spontaneity is the force that motivates the person to appropriate and constructive responses.

Creativity: The creative work is always related to spontaneity. "It can be said that spontaneity is the force that preserves the vitality of the living

33 E. Artzi, Psychodrama; H.A. Blatner, Acting in Practical Applications, p. 27-30; E. Naharin, A Stage instead of a Sofa, Tel Aviv 1986.

34 T. Dayton, The Drama Within.

${ }^{35}$ M. Karp, P. Homs, Classical Psychodrama: An Overview: Inspiration and Technique, London 1991.

${ }^{36}$ Z.T. Moreno Psychodrama, Surplus Reality. 
spring inside of us and the inspiring power in it; creativity is the welling and flowing of the spring. ${ }^{37}$

Moreno ${ }^{38}$ spoke about five fundamental elements: protagonist, instructor, auxiliary ego, group, and stage, and about many techniques.

Psychodrama enables the reconstruction of the participant's experiences in the framework of the peer group and with the help of its members.

\section{Non-Formal Perspective}

From a non-formal perspective, there are programs that are operated after the school hours, in the Department of Youth Promotion, in the municipality youth centers, in the community clubs, and in the psychological welfare service. These programs provide activities such as mental support and help in their homework preparation. At the end of the school year, in the summer vacation, there are special programs for transition and for the prevention of risk behaviors because of the transition. Additionally, in the summer vacation, there is out door training (ODT): paintball, carting, challenging sports, prevention of alcohol use, prevention of violence online, and so on.

\section{Summary}

The Israeli educational system places special emphasis on the identification and treatment of adolescents at-risk in the period of transition from middle school to high school. This period of transition is characterized itself by pressures of adolescence for normative adolescents and is even more stressful for adolescents at-risk, who have additional special difficulties. The Israeli educational system has a holistic treatment approach for adolescents at-risk, which includes identification, treatment, and supervision in the school and supervision and assistance in the hours after school. The treatment is individualized and/or group treatment and was developed particularly so as to provide a solution to the special problems of adolescents atrisk.

37 E. Artzi, Psychodrama. 1991, Dvir Press, p. 23.

38 Z.T. Moreno Psychodrama, Surplus Reality. 


\section{BIBLIOGRAPHY}

Antonovsky A., The Salutogenic Model, Trends, 1987.

Arnett J., American Storm and Stress, Reconsidered, American Psychologist, 1999, 54(5).

Artzi E., Psychodrama, Dvir Press, 1991.

Ben-Rabi D., Kahan-Starvinsky P., Planning Services and Interventions for Children and Youths at the Edge of the Risk Continuum, Brookdale Institute, Joint Jerusalem, Jerusalem 2003.

Binstock A., Kit On Normative Transitions in the Educational System, 2004, From: The Psychological Counseling Service Website, In The Ministry of Education Website, Www.Cms.Education.Gov.Il.

Blatner H.A., Acting In Practical Applications of Psychodrama Methods, Springer Publisher Com. Inc., 1973.

Blos P., On Adolescence, The Free Press, New York 1962.

Blos P., The Adolescence Passage: Developmental Issues, International University Press, New York 1979.

Cohen-Navot M., School Intervention for Children and Youths At-Risk, Special Report, Background Document For Eshelim, [in:] The Framework of the Formation of a Three-Year Work Plan, 2004-2006, Meyers-Joint-Brookdale Institute, Jerusalem 2003.

Dayton T., The Drama Within: Psychodrama and Experiential Therapy, Health Communications, Deerfield Beach, FL 1994.

Dovrat S., The National Plan for Education: Report of the National Task Force for the Promotion of Education in Israel, The Ministry of Education, Culture, and Sport, Jerusalem 2005.

Dryfoos J.G., Adolescents At Risk: Prevalence and Prevention, Oxford University Press, New York 1990.

Elitzur A., Tiano S., Munitz H., Noyman M., Selected Chapters in Psychiatry, Papyrus, Tel Aviv 2002.

Erikson E.H., Childhood and Society, Hapoalim, Tel Aviv 1960.

Feuerstein R., Lecture on the Topic of Transitions in Education, From: Transitions in Education, Shachar Department - Ministry of Education, 1981.

Glenn H.S., Nelson J., Raising Self-Reliant Children in a Self-Indulgent World: Seven Building Blocks for Developing Capable Young People, Rocklin, California 1988.

Goldshmit N., Raz N., Tori Tz., Treatment Groups for Children with Difficulties in the Social Realm: Theory and Practice, Collection, 2008, 13(1).

Hall G.S., Adolescence, Appleton, New York 1904.

Havighurst R.J., Developmental Tasks and Education 3rd Ed, McKay, New York 1972.

Israeli Association For Psychodrama: Http:/ /Www.Iafp.Org.Il/.

Karp M., Homs P., Classical Psychodrama: An Overview: Inspiration and Technique, Rutledge, London 1991.

Kellerman F.K., Focus on Psychodrama: The Therapeutic Aspects of Psychodrama, Jessica Kingsley, Philadelphia 1992.

Kramer E., Art as Therapy For Children, Reshafim Press, New York 1971.

Lahad M., Basic Ph: The Story of Coping Resources, [in:] Community Stress Prevention, Volumes 1 and 2, Eds. M. Lahad, A. Cohen, Community Stress Prevention Center, Kiryat Shemona, Israel 1997.

Lahav H., Youth in the Margins Of Society - The Phenomenon and Ways of Coping, Ministry of Education and Culture, Administration of Society and Culture, Jerusalem 1999. 
Ministry of Education of Israel, "Rationale of the Educational Continuum", From the Ministry of Education Website, www.cms.education.gov.il

Moreno Z.T., Psychodrama, Surplus Reality and the Art of Healing, Routledge, London and Philadelphia 1921.

Muss R.A., Theories on Adolescence, Sifriat Poalim, Tel Aviv 1988.

Naharin E., A Stage instead of a Sofa, Cherikover and Guma Press, Tel Aviv 1985.

Noy P., The Normal Processes for the Maintenance of the Sense of Self - The Relations with Others and the Group, Conversations, 1999, 14(1).

Riley S., Art Therapy with Adolescents, Ach, Kiryat Bialik, 2008.

Rosenwasser N., Group Instruction - A Reader, The Haim Zippori Center of Education, The Community Center Society, Jerusalem 1997.

Shmidt H., The Prime Minister's Committee for Children and Youths At-Risk, Report of the Public Committee for the Examination of the Situation of Children At-Risk and in Distress, 2006.

Smilansky M., The Challenge of Adolescence: Acquaintance and Friendship, Tel Aviv University, Tel Aviv 1988.

Sroufe L., Cooper R., Dehart J., The Development of the Child: Nature and Process, Volume 2, The Open University, Tel Aviv 2004.

Steinberg L., Identity. Adolescence, McGraw-Hill Inc., Boston 2002.

Turner V., The Ritual Process: Structure and Anti-Structure, Ressling, 2009.

Van Gennep A., The Rites of Passage, Routledge and Kegan Paul, London 1977.

Yinon Y., Rodniki Y., Influence of the Rise to the Middle School on the Student Anxiety and Aggressiveness as a Function of Social-Economic Status, Studies in Education, 2003, 5(2).

Ziv A., Adolescence, Tel Aviv University, Masada, Tel Aviv 1984.

Ziv Y., Baharav Y., Group Journey: The Guide for the Instructor of Groups, Gal Press, 2001. 